\title{
Maternal Outcome in Twin Pregnancy-Study at a Tertiary Care Centre in South India
}

\author{
Authors \\ Dr Roshni $\mathbf{R}^{1}$, Dr Rani Lakshmi $\mathbf{S}^{2}$ \\ ${ }^{1}$ Assistant Professor' Department of Obstetrics and Gynaecology, Govt. Medical College Hospital, \\ Kottayam, Kerala, India \\ Email:drroshnir@gmail.com \\ ${ }^{2}$ Assistant Professor, Department of Obstetrics and Gynaecology, Govt. Medical College Hospital, \\ Kottayam, Kerala, India \\ Email: ranilprem75@gmail.com
}

\begin{abstract}
Background: Twin pregnancy is considered as a high risk pregnancy with many complications to the mother and the foetus. This study aims to assess the maternal outcome in twins

Materials and Methods: A prospective study was conducted in a tertiary centre in south India over a period of one year. A total of 200 cases of twin pregnancies was followed up from the antenatal period upto their admission to ward and labour room.

Results: Incidence of twin pregnancy was $1.6 \% .76 \%$ were in the age group of 20 to 29 years and primigravidae contributed $49.5 \%$ of the total. Maternal complications noted were anemia in 43(21.5\%) gestational hypertension in 50(25\%)preterm labour in 36(18\%)PROM in 63(31.5\%) hyperemesis in $25(12.5 \%)$ antepartum haemorrage in 12(6\%) Gestational diabetes mellitus in 16(8\%). Among postpartum complications postpartum hemorrhage contributed 34 (17\%). No maternal mortality occurred in the study population. Vaginal delivery was possible in $63.5 \%$ and the rest underwent LSCS. The commonest indication for caesarian section was non vertex first baby (36.5\%).

Conclusion: This study brings to light the complications associated with twin pregnancy. Regular and frequent antenatal checks are required for the prompt diagnosis of maternal complications and to prevent maternal mortality and morbidity. Proper counseling regarding the mode of delivery is required. The need to deliver them in hospitals with facilities for maternal and neonatal intensive care is essential.
\end{abstract}

Keywords: Maternal Outcome, Twin Pregnancy, maternal complication.

\section{Introduction}

Multiple births are much more common today than they were in the past due to the dramatic increase in the use of ovulation inducing agents, assisted reproductive technologies and a shift towards elderly primigravida and grand multiparity, where multiple gestations are more likely to occur naturally ${ }^{1}$ Twin gestation is considered as a high risk pregnancy. In India, twinning occurs in approximately $1 \%$ of all pregnancies and has been reported to be responsible for $10 \%$ of perinatal mortality $^{2}$ This extraordinary increase in multiple births is a public health concern because these infants are less likely to survive and more likely to suffer lifelong disability due to preterm delivery. 
Twins account for $94 \%$ of all multiple births each year

Multiple pregnancies poses definite risks not only to the mother but also to the foetuses. Complications may occur during antenatal, intrapartum and postpartum period. The complications are an increased incidence of hyperemesis gravidarum, pregnancy induced hypertension, polyhydramnios, preterm labour, abnormal presentations, uterine inertia and postpartum uterine atony. Most grave and common complication of twin pregnany is preterm birth that increases the short and long term perinatal morbidity and mortality In addition to the traditional indicators of perinatal morbidity and mortality, twin pregnancies are associated with a number of financial, personal and social costs for their families and twins themselves. This study endeavors to evaluate the increased risks to the mother and hopes to suggest remedial measures to improve the maternal outcome

\section{Materials \& Methods}

A prospective study was conducted at. Department of Obstetrics and Gynaecology, Institute of Maternal and Child Health, Calicut. 200 cases of twin pregnancies beyond 28 weeks of gestation admitted during this period were taken as the study group. Pregnancies with more than 2 children were excluded from the study. 200 cases of twin pregnancies more than 28 weeks were followed from the antenatal period upon their admission to the antenatal ward and the labour room. Detailed history was taken. Age of the patient, parity and history of having taken any ovulation induction drugs were noted. Family history of twinning was asked. History of any antenatal complications in the 3 trimesters was noted. The mode of onset of labour whether spontaneous or induced and mode of delivery whether abdominal or vaginal were evaluated. Presentation of fetuses were noted at the time of delivery The usual investigations were done in all cases and special investigation (like $\mathrm{PIH}$ profile, FBS, PPBS, Doppler ultrasound) etc were done whenever necessary. Antenatal corticosteroids were given routinely in all cases presenting with preterm labour and in complicated cases needing early termination. Induction was required in some cases for various obstetricl indications. Detailed clinical examination, local examination and per vaginal examination was also recorded. In labour, patients were watched for progress. Once the first twin delivered, per abdominal examination and a per vaginal examination was repeated and delivery of the second twin was facilitated. Blood was arranged in almost all cases and active management of third stage of labour was practiced. Chorionicity of placenta was noted after delivery of both the babies. Time interval between the delivery of the twins was noted. The study was approved by institutional ethical committee Statistical analysis was performed using Chi-square test and the significance was assumed at $\mathrm{p}$ value of $<0.05$.

\section{Results}

Total number of deliveries during the study period was 21,718. Twins constitute 347 deliveries [1.6\%]. 200 cases of twin pregnancies during the study period were studied in detail and taken for analysis. Twinning has a maximum incidence between20-24yrs[table-1] it is seen that out of the 200 cases 99 cases ie $49.5 \%$ are primigravida. 66 cases [33\%] were second gravida, 25 cases ie $12.5 \%$ are third gravida. Gravida 5 and above constitutes only $2.5 \%$.[table 2]

Table 1 Maternal age distribution

\begin{tabular}{|l|c|c|}
\hline Age & Case & Percentage \\
\hline $15-19$ yrs & 23 & 11.5 \\
\hline $\mathbf{2 0}-\mathbf{2 4}$ yrs & $\mathbf{8 6}$ & $\mathbf{4 3}$ \\
\hline $\mathbf{2 5}-\mathbf{2 9}$ yrs & $\mathbf{6 6}$ & $\mathbf{3 3}$ \\
\hline $30-34$ yrs & 20 & 10 \\
\hline$\geq 35$ yrs & 5 & 2.5 \\
\hline Total & 200 & 100 \\
\hline
\end{tabular}

Table 2: Incidence in relation to gravidity

\begin{tabular}{|l|c|c|}
\hline Gravidity & Number & Percentage \\
\hline Primi & $\mathbf{9 9}$ & $\mathbf{4 9 . 5}$ \\
\hline $\mathbf{G}_{\mathbf{2}}$ & $\mathbf{6 6}$ & $\mathbf{3 3}$ \\
\hline $\mathrm{G}_{3}$ & 25 & 12.5 \\
\hline $\mathrm{G}_{4}$ & 5 & 2.5 \\
\hline $\mathrm{G}_{5}$ and above & 5 & 2.5 \\
\hline Total & 200 & 100 \\
\hline
\end{tabular}

History of ovulation induction was there in 31 casesie $15.5 \%$. 30 of them were induced with 


\section{JMSCR Vol||07||Issue ||03||Page 187-192||March}

clomiphene for an average duration of 3 cycles. One lady had gonadotropin injection. 28 cases gave family history of twinning, majority from the maternal side. Incidence of maternal complications were listed inTable-3

Table 3: Analysis of maternal complications

\begin{tabular}{|l|c|c|}
\hline Maternal complications & Number & Percentage \\
\hline Threatened abortion & 7 & 3.5 \\
\hline Hyperemesis & 25 & 12.5 \\
\hline Gestational hypertension & $\mathbf{5 0}$ & $\mathbf{2 5}$ \\
\hline Mild preeclampsia & 22 & 11 \\
\hline Severe preeclampsia & 25 & 12.5 \\
\hline Eclampsia & 1 & 0.5 \\
\hline HELLP & 2 & 1 \\
\hline Anemia & 43 & 21.5 \\
\hline Gestational Diabetes Mellitus & 16 & 8 \\
\hline Hydramnios & 9 & 4.5 \\
\hline Abruption placentae & 6 & 3 \\
\hline Placenta previa & 6 & 3 \\
\hline Preterm labour & $\mathbf{3 6}$ & $\mathbf{1 8}$ \\
\hline PROM & $\mathbf{6 3}$ & $\mathbf{3 1 . 5}$ \\
\hline PPH - Mild & 21 & 10.5 \\
\hline Severe & 13 & 6.5 \\
\hline
\end{tabular}

There was PROM in 63 cases [31.5\%]. 30 cases [47.6\%] had onset of PROM between 35- 37 weeks. Preterm labour was detected in 36 cases (18\%). Among the study population 47 percent had onset between 35-37 wks and 39 percent presented between 32- 34 weeks.90 cases had preterm deliveries [45\%]. 31 cases were induced for various reasons. Main reasons for induction are pregnancy induced hypertension and its complications, intrauterine growth restriction, PROM, unfavorable cervix and early cases of single fetal demise. Majority of cases ie $55 \%$ had gestational age between 35-37 wks at the onset of labour. 28\% had onset between 38 and 40 wks. Most common presentation was vertex- vertex amounting to $48 \%$ of the cases. Next common is vertex-breech $(22 \%)$. Breech-breech presentation (10.5\%.) and breechvertex (14\%). 3 cases had vertex- transverse presentation.[Table-4]
Table: 4 Analysis of the frequency of presentation

\begin{tabular}{|l|c|c|}
\hline Presentation & Number & \% \\
\hline Vertex - vertex & $\mathbf{9 6}$ & $\mathbf{4 8}$ \\
\hline Vertex-breech & 44 & 22 \\
\hline Breech-breech & 21 & 10.5 \\
\hline Breech-vertex & 28 & 14 \\
\hline Vertex-transverse & 3 & 1.5 \\
\hline Others & 8 & 4 \\
\hline Total & 200 & 100 \\
\hline
\end{tabular}

$63.5 \%$ had normal vaginal delivery. $36.5 \%$ required caesarian section .4 cases needed caesarian for the second baby after delivery of the first twin. 40 cases had assisted breech delivery of the second twin.[Table-5\&6] Among the indications of caesarean section $36.8 \%$ were for $1^{\text {st }}$ baby nonvertex, $14.5 \%$ for pregnancy induced hypertension and its complications. 4 cases were done for $2^{\text {nd }}$ of twin, 1case for foetal distress, and remaining 3 cases for failed internal podalic version for the $2^{\text {nd }}$ baby having transverse lie[Table 7]

Table: 5 Analysis according to mode of delivery

\begin{tabular}{|l|c|c|c|c|}
\hline \multirow{2}{*}{ Mode of delivery } & \multicolumn{2}{|c|}{ First twin } & \multicolumn{2}{c|}{ Second twin } \\
\cline { 2 - 5 } & Number & $\%$ & Number & $\%$ \\
\hline $\begin{array}{l}\text { Vaginal delivery } \\
\text { (Vx) }\end{array}$ & $\mathbf{1 0 3}$ & $\mathbf{5 1 . 5}$ & $\mathbf{8 1}$ & $\mathbf{4 0 . 5}$ \\
\hline $\begin{array}{l}\text { Assisted breech } \\
\text { delivery }\end{array}$ & 19 & 9.5 & 40 & 20 \\
\hline Vaccum & 6 & 3 & 3 & 1.5 \\
\hline Forceps & 1 & 0.5 & 1 & 0.5 \\
\hline Elective CS & 16 & 8 & 16 & 8 \\
\hline Emergency CS & $\mathbf{5 5}$ & $\mathbf{2 7 . 5}$ & $\mathbf{5 9}$ & $\mathbf{2 9 . 5}$ \\
\hline Total & 200 & 100 & 200 & 100 \\
\hline
\end{tabular}

Table : 6 Mode of delivery

\begin{tabular}{|l|c|c|}
\hline Vaginal & 254 & $63.5 \%$ \\
\hline Abdominal & 146 & $36.5 \%$ \\
\hline Combined vagino abdominal & 4 & $1 \%$ \\
\hline
\end{tabular}

Table: 7 Indication for caesarean section

\begin{tabular}{|l|c|c|}
\hline Indications & Number & \% \\
\hline First baby non vertex & $\mathbf{2 8}$ & $\mathbf{3 6 . 8}$ \\
\hline Previous caesarean section & 7 & 9.2 \\
\hline PIH and its complications & 11 & 14.57 \\
\hline PROM, failed induction & 3 & 3.9 \\
\hline Dysfunctional labour & 6 & 7.8 \\
\hline Placenta previa & 2 & 2.6 \\
\hline Foetal distress & 3 & 3.9 \\
\hline Monoamniotic & 1 & 1.3 \\
\hline $2^{\text {nd }}$ twin & 4 & 5.3 \\
\hline Cord prolapsed & 2 & 2.6 \\
\hline Others & 9 & 11.8 \\
\hline
\end{tabular}




\section{Discussion}

Table 1 shows the maternal age distribution in twins. $43 \%$ belonged to $20-24$ age group. $33 \%$ belonged to 25-29yrs of age. Mothers older than $35 y$ rs amounted to only $2.5 \%$. This compares well with a retrospective analysis of 188 twin pregnancies conducted at LTMG Hospital, Mumbai by Anahita et al, where also the maximum incidence was between 21 - 25 years of age ${ }^{3} .49 .5 \%$ were primigravidas. Grand multi constituted only $2.5 \%$. The positive effects of increasing maternal age and parity on twinning were well demonstrated by Waterhouse. The reason for the reduction in the incidence of pregnancies in grand multi may be due to implementation of effective family planning methods. Increased incidence in primigravida may be because they account for the largest percentage in the study population and $15 \%$ conceived after treatment for infertility. This was similar to the study by Dubey et $\mathrm{al}^{4} \&$ PyrbotJEet $\mathrm{al}^{5} .31$ cases gave history of ovulation induction $(15 \%)$ ( Table 3$), 30$ cases took clomiphene and 1 case had gonadotropin as the mode of induction. Mahmut et al in a retrospective analysis of 261 cases of twin pregnancies reported ovulation induction in $10.25 \%{ }^{6}$. Table 4 shows the incidence of maternal complications in twin pregnancies. In this study $25 \%$ had gestational hypertension. $12.5 \%$ had severe preclampsia. There was 1 case of eclampsia and 2 cases of Hellp syndrome. A recent, large, prospective trial by Sibai et al also confirmed a significantly increased risk $(12.9 \%)$ for gestational hyperternsion and $12.7 \%$ for preeclampsia in twins compared to singletons ${ }^{7}$. Women with a twin gestation complicated by gestational hypertension or preeclampsia are more likely to have a pregnancy that results in preterm delivery, a low birth weight infant or caesarean birth in comparison to women with a singleton pregnancy. The association between twins \& hypertention was also supported by Walker et al 2004 \& Gyamfi $2005 .{ }^{8}{ }^{8}$ Anemia is a common complication of twin pregnancy. The present study shows the incidence to be $21.5 \%$. The incidence of anaemia varies in different studies. Increased incidence in our population may be because the majority of the study population belongs to a low socioeconomic status. The cutoff for defining anaemia may be different in various studies. In our study it was taken as $11 \mathrm{gm} \%$. Higher rates of anemia is in line with previous reports [Qaizi 2011 ${ }^{10}$ ] Other complications encountered were diabetics in $8 \%$ cases, hydramnios in $4.5 \%$ of cases and APH in $6.5 \%$ (6 cases of abruption, 6 cases of placenta previa) The risk of PPH is higher in multiple pregnancies because of the increased placental site, uterine over distention and greater tendency to uterine atony. Postpartum hemorrhage was there in $17 \%$ cases, 18 cases having severe PPH requiring blood transfusion. One case ended up in hysterectomy as the patient went into DIC. This shows the importance of anticipating all these complications when dealing with a case of twin pregnancy. Another most important complication found more frequently in twin pregnancies leading to an increased morbidity and mortality is preterm labour. Preterm labour complicated $18 \%$ of the cases. Among them the majority had onset between 35-36wks, $40 \%$ between 31-34 wks, adding to the bulk of perinatal morbidity. The general incidence varies in different studies between 20-75\%. In a retrospective of analysis of 261 twin pairs Mahmut et al reported the incidence of preterm labour as $23 \%$ and PROM as $8.8 \%$. In the present study premature rupture of membranes was identified in $31.5 \%$, 46\% had onset between 35-37 weeks. Preterm birth is the main reason for the poor perinatal outcome in multiple pregnancy. Incidence of preterm delivery in the present study was $45 \%$. $84.5 \%$ of twins had spontaneous onset of labour, but in $15.5 \%$ (31 cases) labour was induced for obstetrical indications like PIH and its complications, intrauterine growth restriction, PROM and unfavourable cervix and for cases of single fetal demise. Majority of cases ie $55 \%$ had delivery between 35 and 37 weeks and $28 \%$ delivered between 38 and 40 wks. 13\% delivered between 32- 34 weeks. This shows that the average gestational age in twins is 2-3 weeks prior to singleton pregnancy. Yin Bin Cheung et $\mathrm{al}^{11}$ suggested the optimal gestational age to twins to be 
between 37 - 39 weeks; this is associated with minimum neonatal and infant morbidity and mortality. There is a high incidence of malpresentation at the time of delivery in twin gestation. The most common presentation in the present study was vertex- vertex (48\%). Next common is vertex-breech in 44casesThis was comparable to the study by Chowdhary et al ${ }^{12}$ In our study 49 cases (24.5\%) had breech as presentation for the first baby. $57 \%$ of these cases were delivered by caesarean section. This substantiates that malpresentations are more in twin pregnancy. In this study $63.5 \%$ (254babies) delivered vaginally, when compared to $36.5 \%$ [146 babies] delivered by caesarean section. The incidence of caesarean section was definitely more in twin pregnancy when compared to singletons. $27.5 \%$ had required emergency caesarean section and $8 \%$ delivered by elective caesarean section. This was comparable to various other studies as shown in the table below. In our study 4 cases had reported caesarean section done for the delivery of the $2^{\text {nd }}$ twin. In 3 of them lie of the $2^{\text {nd }}$ baby was transverse. After delivery of $1^{\text {st }}$ twin. internalpodalic version was tried in these cases, but failed and they ended in caesarean section. In one case indication for section for $2^{\text {nd }}$ baby was foetal distress. In 40 cases $2^{\text {nd }}$ twin was delivered by assisted breech delivery. In other studies the cs rate was even higher $52 \%$ by Pyrbot et al\&68\% by Shelly et al ${ }^{13}$ There is an increasing trend in cs rate in twins over the decade. Most women wanted cs due to apprehension. Also obstetricians anxiety and their concern while managing infertility may increase the cs rate in these patients, although studies have suggested that the outcomes are not improved by $\mathrm{cs}^{14}$ So, the common indication for CS was noncephalic first twin, in which caesarean delivery is often preferred and advised, although no series suggests that vaginal birth is inappropriate. Most common indication was similar to study by Yasmeen $\mathrm{s}^{15}$

\section{Conclusion}

Twin pregnancy carries an increased risk of maternal complications such as gestational hypertension, anemia, antepartum hemorrhage, postpartum hemorrhage, PROM, preterm labour in twins Timely detection of antenatal risk factors and appropriate management will improve outcome. Twins pregnancies are associated with increased incidence of malpresentations and hence increased operative deliveries, which was $36.5 \%$ in the present study. Strict intrapartum monitoring, experienced obstetricians to conduct delivery, liberal use of LSCS along with good neonatal intensive care especially for premature babies, will lead to better outcome.

\section{Acknowledgement}

We are extremely thankful to Prof. Dr.Sreedevi N.S, and Dr.Vinayachandran, Department of Obsterics and Gynecology, IMCH, Calicut for the valuable suggestions and guidance.

We also express our sincere thanks to all the patients who participated in our study.

Above all, we are grateful to Almighty God for his blessings that have led to the completion of this study.

\section{References}

1. American society of reproductive medicine. Multiple pregnancy and birth, considering infertility treatment: twin, triplets \&higher order multiples;2004.

2. Vidyadhar B.Bangal., Shruti $m$ Patel, Devendra N Khairnar."Study of maternal\& fetal outcome in twin gestation at tertiary teaching hospital", International journal of Biomedical \& Advanced Research, 2012:03[10]

3. Anahita Pandole, M.S.C. Swamy, Nagendra Sardesh Pande, Anjali Mishra, Shailesh J Kore, VR Ambiye. J Obstet Gynecol Ind. Vol 53: No.2: March/April 2003 pg 138 139

4. Dubey et al.Int J Reprod Contracept Obstet Gynecol 2018 Sep;7(9):3753-3757 
5. Pyrbot JE, Agarwal $M$ Twin pregnancymaternal \& fetal complications\& its association with mode of delivery a study in a tertiary centre (Int J Reprod Contracept Obstet Gynecol 2017.6 5089-94)

6. Mahmut Erdemoolu, Ahmet Kale, Nurten Akdeniz, Abmet Yalynkaya, Yylmazozcan, Murat Yayla. Perinatal Journal 2005; 13(4): $213-217$.

7. Sibai B, Hauth J, Caritis $S$ et al. Hypertensive disorders in twin versus single ton gestations. Am J ObstetGynaecol 2000; 182: 938- 942.

8. Walker, M.C., Murphy, K.E, Pan, S, Yang, Q., Wen, S.W.2004. Adverse maternal outcomes in Multifetal pregnancies. BJOG;111:1294e1296..

9. Gyamfi, C., Stone, J.,Eddleman, K.A. 2005. Maternal complications of multifetal pregnancy. Clin Perinatol;.32:431e442

10. Qazi, G.2011. Obstetric perinatal outcome of multiple pregnancy. J Coll Physicians Surg Pak;21(3):142-145

11. Yin Bun Cheung, Paul Yip. Mortality of twins and singletons by gestational age. American Journal of Epidemiology, Vol.152, No.12:1107-1116

12. Chowdhary, S., Hussain, M.A.2011. Maternal complications in twin pregnancies. Mymensingh Med J.,20(1):83-7

13. Shelly MB et al.Int J Reprod Contracept Obstet Gynecol.2016 Jan;5(1):217-219

14. Ganchimeg $T$, et al Mode\& timing of twin delivery and perinatal outcomes in low and middle income countries: a secondary analysis of the WHO Multi country Survey on Maternal and newborn Health. BJOG.2014;121(1):89-100

15. Rather S.Y. Studying pregnancy outcome in twin gestation in developing world. IOSR JDMS 2014;13(5):2279-0853. 